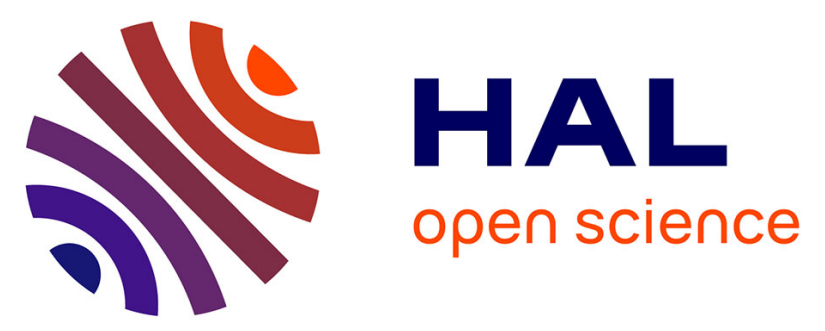

\title{
Leak detection in water transmission systems by multispectral remote sensing with airplane and UAV
}

Christian Chatelard, Javier Sanchis Muñoz, Jean-Claude Krapez, Christophe

Mazel, Vincent Olichon, Juan Barba Polo, Yves-Michel Frédéric, Franck

Hélias, Philippe Barillot, I. Legoff, et al.

\section{To cite this version:}

Christian Chatelard, Javier Sanchis Muñoz, Jean-Claude Krapez, Christophe Mazel, Vincent Olichon, et al.. Leak detection in water transmission systems by multispectral remote sensing with airplane and UAV. IGARSS 2019, Jul 2019, YOKOHAMA, Japan. 10.1109/IGARSS.2019.8900288 . hal02397285

\section{HAL Id: hal-02397285 \\ https://hal.science/hal-02397285}

Submitted on 6 Dec 2019

HAL is a multi-disciplinary open access archive for the deposit and dissemination of scientific research documents, whether they are published or not. The documents may come from teaching and research institutions in France or abroad, or from public or private research centers.
L'archive ouverte pluridisciplinaire HAL, est destinée au dépôt et à la diffusion de documents scientifiques de niveau recherche, publiés ou non, émanant des établissements d'enseignement et de recherche français ou étrangers, des laboratoires publics ou privés. 


\title{
LEAK DETECTION IN WATER TRANSMISSION SYSTEMS BY MULTISPECTRAL REMOTE SENSING WITH AIRPLANE AND UAV
}

\author{
C. Chatelard ${ }^{1}$, J. Sanchis Muñoz ${ }^{2}$, J.-C. Krapez ${ }^{1}$, C. Mazel$^{3}$, V. Olichon ${ }^{3}$, J. Barba Polo², \\ Y.-M. Frédéric ${ }^{1}$, F. Hélias ${ }^{1}$, P. Barillot ${ }^{1}$, I. Legoff ${ }^{4}$, G. Serra ${ }^{4}$ \\ ${ }^{1}$ ONERA The French Aerospace Lab, 13300 Salon de Provence, France \\ ${ }^{2}$ Galileo Geosystems, Manises 46940, Valencia, Spain \\ ${ }^{3}$ Air Marine, 33850 Léognan, France \\ ${ }^{4}$ SCP, Le Tholonet 13182 Aix-en-Provence, France
}

Corresponding author: christian.chatelard@onera.fr

\begin{abstract}
Water leak detection in water transportation mains outside urban areas by airborne remote sensing has been assessed with a series of measurement campaigns in 2017 over SCP (Société du Canal de Provence - France) network in Provence (Fr). The most appropriate wavelengths and combination for revealing high moisture areas and artificial leaks coming from this image database (VNIR, SWIR, TIR spectral range) allowed us to select the best onboard instrumentation for both types of platforms (manned \& unmanned). This work aims at validating the choice of this instrumentation associated with the multispectral approach (Triangle method) in the framework of a new airborne campaign in October 2018 with a plane and an UAV in operational environment.
\end{abstract}

\section{INTRODUCTION}

Water loss in the transmission networks is a perennial problem which challenges the efficiency of water transmission systems and represents a waste of limited natural resources. Water has become increasingly scarce and less predictable [1]. In some places of Europe as much as $50 \%$ of water resources are being lost before they reach the end-user [2]. Solutions shall address the problems Europe is facing, e.g. $60 \%$ of European cities over-exploit their groundwater resources and 50 percent of wetlands are endangered [3], which could get worse if a more efficient and sustainable use of water resources is not achieved. Problems with leakages are not only related to the efficiency of the network but also to water quality. The detection of leakages in large diameter mains, which represent a high share of the total water losses, is key but it has been poorly addressed due to the challenges it faces (less frequent access to pipe, high frequency noise is quickly attenuated, multiple travel paths, etc.).

Currently, active leakages in water distribution networks (WDN) are detected and located by ground sensing and monitoring techniques based on the measurement of pressure differences, acoustic sounding and ground penetrating radar. These ground methods become difficult or inadequate for water transmission mains, especially out of urban areas, and for open canals. New efficient and cost-effective pipeline surveillance methods are required.

The water leaks induce soil moisture which can reach the upper surface by diffusion and capillarity depending on the pipe damage severity. In a vegetation context, water leaks increase the water content in the vegetation canopy and the vegetation vigour.

Remote sensing offers the possibility of large, medium and field-scale soil moisture monitoring and characterization relying on variations of reflectance in optical bands or emission in thermal bands. An increase of the soil moisture induces reflectance changes in both soil and vegetation, and emission changes related to surface emissivity (close to 1 for natural surfaces) and surface temperature. Some visible effects associated to the soil water content are surface darkening, temperature variations due to increased evaporation, thermal inertia of local areas, and on vegetation anomalous growth or vigour.

The Earth-atmosphere energy balance conditions the surface temperature. This balance is affected by the thermal properties of the surface and the underlying horizons. The water presence in soil or vegetation increases the latent heat losses through evaporation or evapotranspiration respectively. These losses reduce the amplitude of the temperature variations related to variations of the radiative flux (e.g. day-night variations) for both soil and vegetation. 
Wet areas should show a lower radiance temperature as compared to drier areas during sunny day hours, whereas the opposite is expected after the sunset and before the dawn [4]. Thermal infrared (TIR) sensors are used on this basis to assess the soil moisture or the evaporation rate over vegetation canopy areas [5-12]. However, the detection accuracy of the TIR $[5,6,10]$ is low leading to false positives and misinterpretations caused by diverse scenarios like dense vegetation or shadows. To overcome this limitation, TIR was combined with visible and NIR data from multispectral or hyperspectral cameras [7, 9, 11, 12]. A combined use of TIR and VIS-NIR data like in the Triangle Method can be used in water leak detection over water transmission pipes and canals to gain accuracy. This method consists in combining the apparent temperature and a vegetation index like NDVI to perform a temperature-NDVI scatterplot for all the pixels over an area with a wide diversity in terms of cover fraction and water content. The name is related to the (roughly) triangle shape of the obtained scatterplot [13-21]. The vertex of the triangle is often truncated, giving a trapezoidal shape. The scatterplot yields to the calculation of a water index for each point or pixel by making a quotient between its relative position with respect to the dry edge and the wet edge of the triangle/trapezoid [13, 15, 18-21].

An airborne remote sensing campaign was conducted during February, April and July 2017 over several areas belonging to the water network infrastructure provided by SCP to evaluate the applicability of the temperature/Vegetation Index space (i.e. the triangle/trapezoid method) in a water leak detection method based on airborne data. The campaigns were driven with ONERA's BUSARD aerial platform instrumented with two hyperspectral Hyspex VNIR and SWIR cameras and a microbolometer infrared camera (FLIR A325 or FLIR A655sc $7.5-12 \mu \mathrm{m})$. The best results were obtained by applying the triangle method fusing a thermal infrared image and a vegetation index image based on a visible image and a NIR image [21].

The aim of this work is to validate the T-VI (Temperature - Vegetation Index) method at different scales by means of a manned aircraft platform and an UAV with data acquired in October 2018 over an area with artificial water leaks (Fig. 1).

\section{METHODS}

An airborne and UAV remote sensing campaign was carried out on October 2018 over several areas belonging to the water network infrastructure of SCP. The aircraft was a Tecnam P2006T operated by Air Marine and instrumented with a Spectrocam VNIR multispectral camera (with 8 custom selected filters: 425, 550, 640, 660, 724, 820, 832.5 and $840 \mathrm{~nm})$, a Noxant Noxcam cooled TIR camera (7.7 $9.3 \mu \mathrm{m})$ and a custom made acquisition software. The flights with the manned platform were performed at an altitude of
$800 \mathrm{~m}$ which led to a spatial resolution of $0.30 \mathrm{~m}$ for the Spectrocam camera and $0.48 \mathrm{~m}$ for the Noxant camera.

The UAV was a custom designed multicopter operated by Galileo Geosystems and instrumented with a Micasense RedEdge 3 VNIR multispectral camera (with five bands: 475, 560, 668, 717 and $840 \mathrm{~nm}$ ) and a microbolometer uncooled FLIR Vue Pro R TIR camera $(7.5-13.5 \mu \mathrm{m})$. The flights with the unmanned platform were performed at an altitude of $50 \mathrm{~m}$ which led to a spatial resolution of $3.4 \mathrm{~cm}$ for the Micasense camera and $6.5 \mathrm{~cm}$ for the FLIR camera. Soil moisture ground measurements have been carried out during the flights in the $5 \mathrm{~cm}$ upper layer with a portable FDR probe over the area of interest to assess the results.

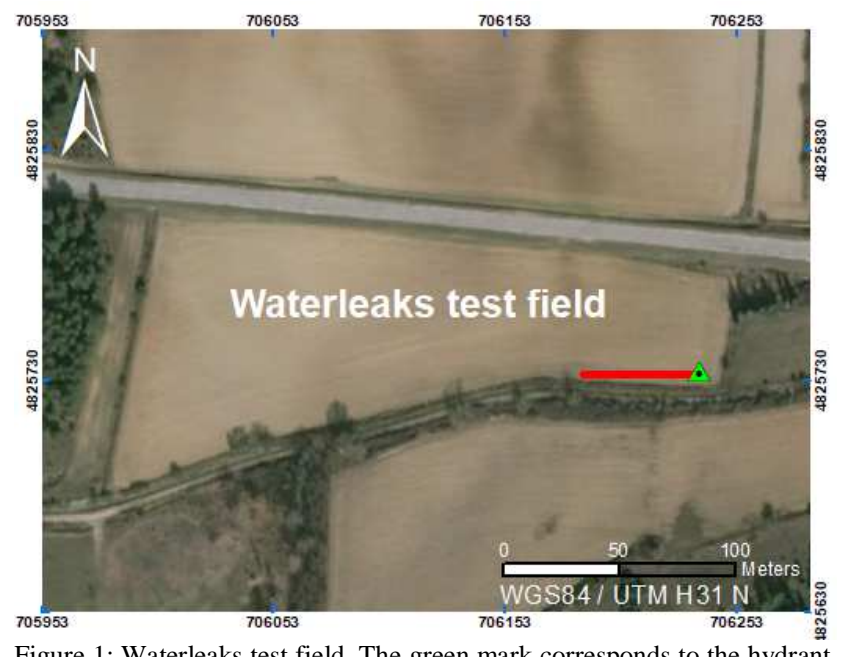

Figure 1: Waterleaks test field. The green mark corresponds to the hydrant. The red line shows the leaking pipeline.

The area of study in the present work is a plot located in Vauvenargues (Aix-en-Provence, France). A secondary pipe has been connected to the existing main pipe and buried at a depth of about $1 \mathrm{~m}$; the connection with the existing pipe was equipped with a valve, a flow meter, a recorder and a pressure regulator; calibrated holes have been drilled in the added pipe to generate leakages.. In the present work three bands have been used in both cases, manned aircraft and UAV (660 nm (red), 832,5 nm (NIR) and TIR for manned aircraft and $668 \mathrm{~nm}$ (red), $840 \mathrm{~nm}$ (NIR) and TIR for UAV). In both cases, the images have been preprocessed with the Pix4D photogrammetric software to obtain spectral orthomosaics. The multispectral aircraft data are uncalibrated raw data. A radiometric calibration based on spectralon calibration images has been applied as part of the radiometric calibration carried out by Pix4D in the case of the red and NIR bands of the UAV acquired data. Although the aircraft and the UAV TIR cameras are both radiometrically calibrated, the emissivity parameter has been set to 1 and no temperature function has been applied to the raw data to extract the true temperature from the brightness temperature. The work in [21] has showed negligible differences between wetness indexes obtained 
from calibrated and uncalibrated optical or thermal data. The rest of the data processing pipeline is similar in both cases. As a first processing step, the spectral mosaics have been normalized and the data range limited to the range $[0$, 1] with the aim of eliminating the "no data" value added by Pix4D. The co-registration of the spectral orthomosaics has been done with Gefolki software developed by ONERA [22] and Pix4D (only the UAV multispectral data). The coregistration has been done taking as master the TIR image as the lowest resolution image in both cases; for this purpose a resampling of the VNIR with a bi-cubic spline interpolation algorithm was performed.

The empirical Triangle/Trapezoid method according to [13] can be implemented by using either NDVI or OSAVI for the vegetation index. OSAVI is expected to have better immunity to the bare soil influence and then it is better correlated to the cover fraction [23]. The water index (WI) is obtained by plotting each pixel of the scene in the temperature - VI space (T-VI). The resulting T-VI scatter plot shows a triangle/trapezoid shape of the pixel distribution. The WI of a pixel at temperature $T_{T I R}$ is calculated following the next expression:

$$
W I=\frac{T_{d r y}-T_{T I R}}{T_{d r y}-T_{w e t}}
$$

where $T_{w e t}$ and $T_{d r y}$ are the lowest and highest temperatures observed at the same VI as the considered pixel. The lowest temperature $T_{w e t}$ belongs to the so-called "cold" edge (or "wet" edge") of the triangle/trapezoid distribution, whereas the highest temperature $T_{d r y}$ belongs to the "warm" edge (or "dry" edge). In the classical Triangle method these edges are straight lines. They can be set automatically or manually, although the best results have been obtained by setting the edges manually.A software called WadiLeaks has been developed by Galileo Geosystems to carry out all the processing steps in a unique graphical user interface.

\section{RESULTS}

The OSAVI images obtained from the VIS and NIR images obtained onboard the airplane and the UAV are reported in Fig. 2. The flight line of the airplane was much larger than the image represented in Fig. 2-top. The latter has itself a much larger extent than the area covered by the UAV (black rectangle in the top image). The spatial resolution obtained by the UAV sensors is nevertheless from 7 to 9 times better. The Temperature-VI scatterplots obtained with the two sets of sensors are reported in Fig. 3. There are unavoidably some differences since the airplane explored a wider region; hence the corresponding scatterplot is more extensively covered.

For each scatterplot, the wet edge (low temperature border) and the dry edge (high temperature border) have been set manually, by excluding only a small number of pixels (outliers). The pixels that are excluded at bottom right of both scatterplot correspond to roads and paths.

The manned aircraft scatterplot is shifted towards lower VI values than those in the UAV scatterplot. This shift is due to the lack of calibration of the VNIR bands from the manned aircraft and doesn't affect the leaks' detection methodology.

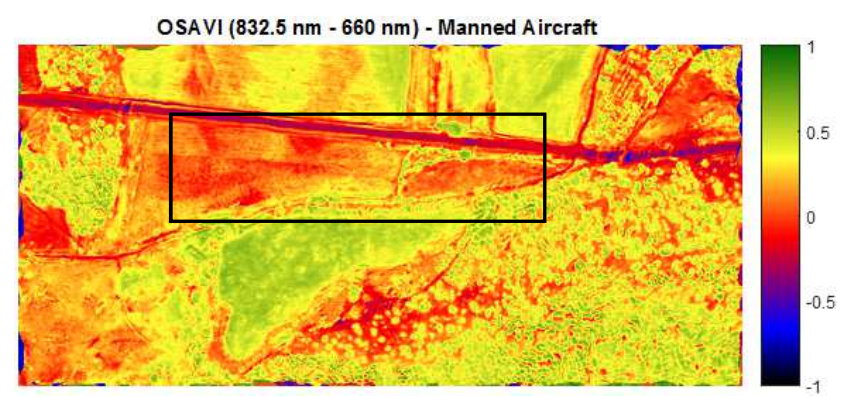

OSAVI $840 \mathrm{~nm}-668 \mathrm{~nm}-$ UAV

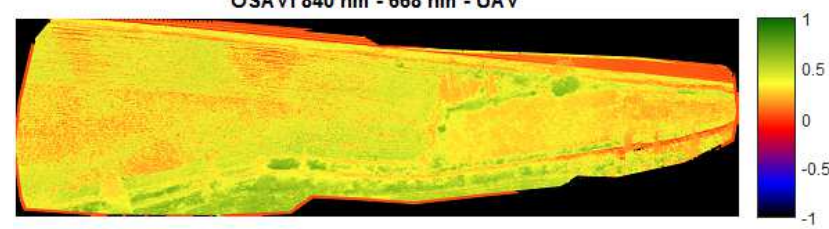

Figure 2: OSAVI vegetation index from the manned aircraft (top) and from the UAV (bottom). The area covered by the UAV in the bottom corresponds approximately to the black rectangle in the top image.
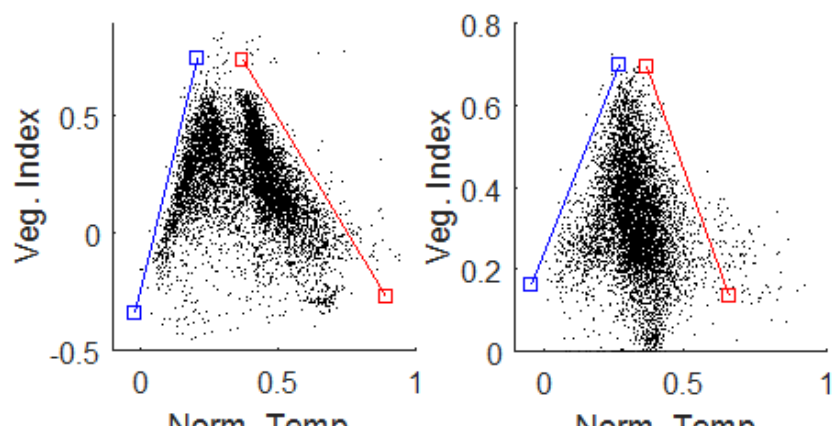

Figure 3: 2D scatterplots of Vegetation Index VI vs. normalized brightness temperature from the manned aircraft (left) and from the UAV (right). The wet edge is in blue and the dry edge is in red.

In the end, the inferred water index maps are reported in Fig. 4. The color scale is such that high moisture areas are in dark blue whereas low moisture areas are in light blue or even in white.

In the area where artificial leaks were present (see the red ellipse), a slight contrast can be observed in both WI images. The ground measurement have shown that the mean moisture level was about $30 \%$ and that it reached locally $60 \%$ at a few points along the leaking line (small puddles could then be seen as well). One should nevertheless admit that the contrast related to the leaks is quite faint; it is of about the same level as the other contrasts naturally developed across the considered field. In addition it is much 
lower than other false signals originating from the vegetation shadows. One explanation is that the campaign occurred one week after a rain period and the soil didn't have time to dry enough. In addition, in October, the solar radiation was not high enough to induce a tremendous difference regarding evaporation between the not-yet-dry surrounding soil and the soil wetted by the leaking line.
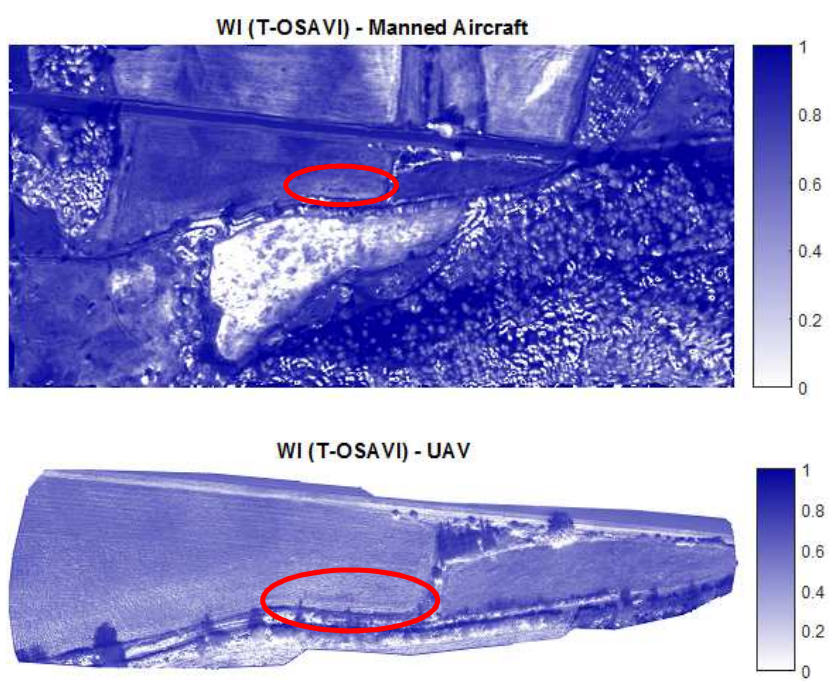

Figure 4: Water index from the manned aircraft (top) and from the UAV (bottom). The leaking area is highlighted with a red ellipse (compare with Fig. 1).

\section{CONCLUSION}

An airborne and UAV remote sensing campaign was performed in October 2018 over SCP water transportation means for acquiring airborne images with both platforms (aircraft and UAV) and for validating in operational conditions the WADI system (sensors, embedded software and on the ground) intended for the detection of water leaks. The multispectral approach has been validated on images of the Vauvenargues site where artificial leaks were introduced (new secondary pipe drilled with calibrated holes connected with the existing pipe) by applying the triangle method fusing a thermal infrared image and a vegetation index upon a visible image and a NIR.

The leaks induced a small contrast in the water index images obtained from both Airplane and UAV. Nevertheless, to achieve a level of contrast that would unarguably be detected against sources of false alarm (i.e. tree shadows), measurements should be done long after a rainy period and during warm seasons (around midday and with a powerful solar irradiance).

\section{ACKNOWLEDGEMENT}

This work has been supported by the EU-funded H2020 project WADI - Water-tightness Airborne Detection Implementation (www.waditech.eu) under grant agreement $\mathrm{N}^{\mathrm{O}} 689239$.

\section{REFERENCES}

[1] William Sarni and Tamin Pechet. "Water Tech: A guide to investment, innovation and business opportunities in the wáter sector". November 2013.

[2] European Commission. "A water blueprint for Europe". 2013.

[3] European Commission. "Water is for life: How the Water Framework Directive helps safeguard Europe's resources" 2010.

[4] V. I. Myer, Crops and soils. In Manual of Remote Sensing, American Society of Photogrammetry, Falls Church, Virginia, (1975) 1715-1813.

[5] M.D. Nellis, Application of thermal infrared imagery to canal leakage detection, Remote Sens. Environ., 12 (1982) 229-234.

[6] J.P. Tracey, P.A. Walton, Hydrologic investigations in canal and aqueduct systems using airborne thermal infrared linescanning, In Geoscience and Remote Sensing Symposium, IGARSS'89 12th Canadian Symposium on Remote Sensing, vol. 5, IEEE (1989) 2815-2819.

[7] J.M. Pickerill, T.J. Malthus, Leak detection from rural aqueducts using airborne remote sensing, Int. J. of Remote Sens. 19 (1998) 2427-2433.

[8] I.J. McGowen, S.L. Duff, I. Smith, Identifying channel seepage using pre-dawn thermal imagery, In Geoscience and Remote Sensing Symposium, IGARSS'01, 4, IEEE (2001) 1631-1633.

[9] Y. Huang, G. Fipps, S.J. Maas, R.S. Fletcher, Airborne remote sensing for detection of irrigation canal leakage, Irrig. and Drain., 59 (2009) 524534.

[10] S.J. Thomson, , C. Ouellet-Plamondon, S.L. DeFauw, Y. Huang, D.K. Fisher, P.J. English, Potential and challenges in use of thermal imaging for humid region irrigation system management, J. Agric. Sci. 4, (2012) 103.

[11] M. Arshad, R. Gomez, A. Falconer, W. Roper, M. Summers, A remote sensing technique detecting and identifying water activity sites along irrigation canals, Am. J. Envir. Eng. \& Sci. 1 (2014) 19-35.

[12] S.L. Cundill, M. Meijde, R.G.K. Hack, Investigation of remote sensing for potential use of dike inspection, IEEE J. Sel. Top. Appl. Earth Obs. Rem. Sens., 7 (2014) 733-746.

[13] I. Sandholt, K. Rasmussen, J. Andersen, A simple interpretation of the surface temperature-vegetation index space for assessment of surface moisture status, Remote Sens. Environ. 79 (2002) 213-224.

[14] T.N. Carlson, An overview of the" triangle method" for estimating surface evapotranspiration and soil moisture from satellite imagery, Sensors, 7 (2007) 1612-1629.

[15] G. P. Petropoulos, G. Ireland, B. Barrett, Surface soil moisture retrievals from remote sensing: Current status, products \& future trends. Physics and Chemistry of the Earth, Parts A/B/C, 83, (2015) 36-56.

[16] J.-C. Krapez, A. Olioso, B. Coudert, Comparison of three methods based on the temperature-NDVI diagram for soil moisture characterization, Proc. of SPIE 7472, 74720 (2009) 1-12.

[17] J.-C. Krapez, A. Olioso, A combination of temperature, vegetation indexes and albedo, as obtained by airborne hyperspectral remote sensing, for the evaluation of soil moisture, J. Quant. Infr. Thermog., 8 (2011) 187200.

[18] J.-C. Krapez, C. Chatelard, J.-F. Nouvel, P. Déliot, Combined airborne thermography and visible-to-near infrared reflectance measurement for soil moisture mapping, QIRT 2012 Conference, 11-14 June 2012, University of Naples Federico II, Naples, Italy.

[19] A. Maltese, C. Cammalleri, F. Capodici, G. Ciraolo, G. L. Loggia, Surface soil humidity retrieval using remote sensing techniques: a triangle method validation, Proc. of SPIE 7824, 782425, (2010) 1-8.

[20] A. Maltese, F. Capodici, G. Ciraolo, G. L. Loggia, Soil water content assessment: Critical issues concerning the operational application of the triangle method, Sensors, 15 (2015) 6699-6718.

[21] C. Chatelard, J.-C. Krapez, P. Barillot, P. Déliot, Y.-M. Frédéric, J. Pierro, J.-F. Nouvel, F. Hélias, Y. Louvet, I. Legoff, G. Serra, "Multispectral approach assessment for detection of losses in water transmission systems by airborne remote sensing", HIC 2018, $13^{\text {th }}$ Int Conf. Hydrodynam., Palermo (It).

[22] G. Brigot, E. Colin-Koeniguer, A. Plyer, F. Janez, Adaptation and evaluation of an optical flow method applied to coregistration of forest remote sensing images, IEEE J. Sel. Topics Appl. Earth Obs. Rem. Sensing, 9 (2016) 2923-2939.

[23] G. Rondeaux, M. Steven, F. Baret, Optimization of soil adjusted vegetation indices, Remote Sens. Environ., 55 (1996) 95-107. 